\title{
Assigning the Potential Places of Life Astacus Leptodactylus in Anzali Wetland using by GIS
}

\author{
Hooshmand Ataei \\ Associated professor of payamnoor University, Tehran, Iran \\ Ali Sajed \\ Lecturer of Islamic Azad University Khosrowshah, Iran
}

Doi:10.5901/mjss.2016.v7n2s2p73

\begin{abstract}
There was a sampling due to the economic importance and bringing ceder of fresh water Astacus Leptodactylus for researching Anzali wetland for assigning the potential places of life for natural growth of this type from 13 station in 13 inflow rivers to it (Bhambarrod,Morghad and Khalkaei, Espand, Kolesar, Chomesghal, Nargestan, Siah darvishan, Hendehkhaleh, Pirbazar, Bijrodack, Ghanadi, Ramezan Bekande, shayjan), the sample of superficial water produced by Nansen bottle and were provided by standard method of APHA and their physical and chemical parameters measured and we used of the book named standared method (standard method for water and waste Analysis) for measuring of BOD,Calcium, total phosphore, total hardness and $\mathrm{NH4}$. These results shows that the average of temperature is between 18.39and 19.25 and the min and max average of soluted oxygen change between 6.28 and $6.9 \mathrm{ppm}$ in 1 to 13 station which these quantities related on the best need of the type. The number of calcium is the most important factor for growing this type, between 58.29 and 67.93 has been changed in 13 station and this is a desired quantities and it doesn't seem that calcium is a limiting factor in growing king prawns in Anzali wetland. King prawn has physiological good capacity for living in $\mathrm{pH}$ between 6.5 and 8 that these quantities are proportionate to obtained average between 7.28 and 7.87 from the station. The effective factors on decreasing the saving of Anzali wetland King prawn can be increase of pollution, different disease, recent droughts, entrance of macrobrachyium, Azola, releasing fish, increasing the hunters, decreasing the average of depth, settling and the time of remaining of wetland salting specially during 2 years ago are the most importance factor for decreasing of this species.
\end{abstract}

Keywords: Anzali wetland, Astacus Leptodactylus, water pollution, Fresh water shrimp,ecological condition,Iran

\section{Introduction}

Anzali wetland is an invaluable wetland and located in north of Iran or south west of Caspian Sea, which due to vast variety of her own plants and aquatics and incurred ecological, economical and social impacts in the region enjoys great and special importance.

King prawn is known Caryfish in different parts of the world. This group belongs to the largest crustaceans named Ten feet and also the only representative of the large forks among crustaceans that inhabit in fresh water and Creeping and walking in the opposite direction of the water (Scholtz G., Richter S., 1995).

Fresh water king prawn are very adaptive physiologically and behaviorally inhabit in static and running waters (quite) underground substrates, semi-dry environment and salty waters-king prawn belong to ten feet crustaceans that are important in the food chain( Harhoglu M.,2003). These animals fed on organic particles and remains of dead organisms, so, they will help to refine the environment of organic matter. Anzali wetland Crayfish named Astacus Leptodactylus that there is in infow rivers is the only fresh water Crayfish and one of the valuable aquatic animals that is important economically, exporting and importing in country (Koksal G.1988). With respect to the importance of this species and potential decreasing in recent years it seems necessary to investiative wetland potentials (habitat) and the ecological conditions needed for such research achieving the related aims and investigate the decreasing reasons. In this purpose, sampling was done in rivers waters leading to Anzali wetland (13satations in 13 rivers and measuring BOD, DO, COD, $\mathrm{pH}$, Turbidity, Calcium, Total phosphorus, total hardness and temperature parameters to study same effective physical and chemical parameters. While investigating above parametars, we investigate other indicators such as environmental conditions, biological pollutants and human activities also have been effective. 


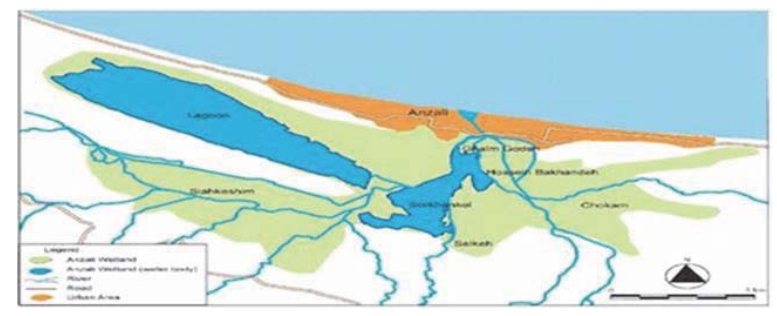

Figure 1: Anzali wetland in the north and south of the Caspian Sea.

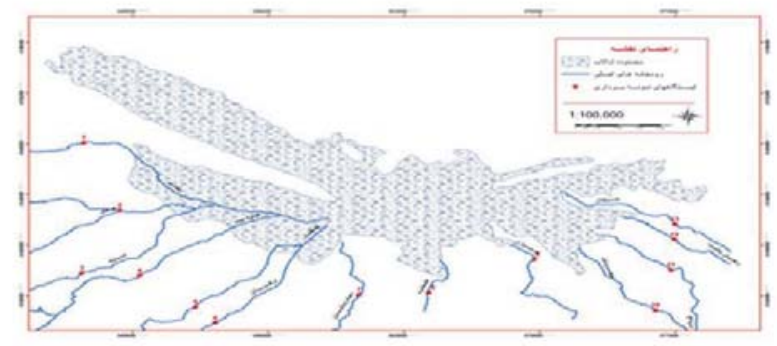

Figure 2: location of sampling stations in the research area.

Table 1: Sampling stations of the research area station number

\begin{tabular}{|lc|}
\hline Main river sampling stations & Station number \\
Bhambarrod & 1 \\
Morghad and Khalkaei & 2 \\
Espand & 3 \\
Kolesar & 4 \\
Chomesghal & 5 \\
Nargestan & 6 \\
Siah darvishan & 7 \\
Hendehkhaleh & 8 \\
Pirbazar & 9 \\
Bijrodack & 10 \\
Ghanadi & 11 \\
Ramezan Bekande & 12 \\
shayjan & 13 \\
\hline
\end{tabular}

\section{Material and Method}

\subsection{The study area}

Write some general information about the study area Don't forget the geographic coordinate system

\section{Sampling of Water}

After a thorough review of the research area, sampling was done in 13 stations in the rivers leading to the Anzali wetland. Superficial water samples were prepared by Nansan bottle and according to standared method APHA (WWA, 2005), preparation and physicochemical parameters were measured.Temparature,turbidity, DO,pH,BOD,Calciums total phosphorous,total hardness was measured by the portable device in the area. 
We used the standared book to measuring method parameters.All sample containers before use were washing by dilute hydrocholoric acid,water and urban water. Safety issues were obserued during the process and if necessary the .....chemicals has been used. Statistical analysis of data(data statistical analysis) we used tables 2 (for locating the best area for inhabitant with respect to the optimum need for species and effective measuring of parameters on data analysis Arc map/Arc GIS species in environment.

Table 2: The species optimum need

\begin{tabular}{|lcc|}
\hline Parameters & & \\
Temperature & $25-20$ & $32-4$ \\
Oxygen mm/lit & $-\overline{-}$ & Until 3.97 \\
pH & $8-6$ & $12-3$ \\
Calcium mg/lit & $100-50$ & $130-5$ \\
\hline
\end{tabular}

Table 3: Mean physical and chemical parameters of stations in the research area

\begin{tabular}{|cccccccccccc|}
\hline $\begin{array}{c}\text { Parameters } \\
\text { Station }\end{array}$ & T & DO & BOD & COD & Turbidity & pH & \multicolumn{7}{c|}{ Total hardness } & Calcium & Total phospore & NH4 \\
1 & 18.39 & 8.37 & 2.28 & 16.3 & 42.33 & 7.46 & 201.83 & 65.32 & 0.194 & 0.254 \\
2 & 18.85 & 9.23 & 2.32 & 16.17 & 38.22 & 7.84 & 188.17 & 67.07 & 0.28 & 0.218 \\
3 & 18.98 & 8.81 & 2.16 & 16.51 & 43 & 7.67 & 201.06 & 66.71 & 0.348 & 0.232 \\
4 & 18.53 & 9.49 & 2.16 & 16.4 & 47.42 & 7.62 & 205 & 67.93 & 0.199 & 0.307 \\
5 & 19.1 & 9.61 & 2.3 & 16.27 & 47.46 & 7.79 & 190.25 & 66.5 & 0.202 & 0.288 \\
6 & 19.12 & 8.76 & 2.2 & 16.6 & 48.58 & 7.57 & 206.83 & 67.71 & 0.325 & 0.214 \\
7 & 18.87 & 9.55 & 2.23 & 16.02 & 31.8 & 7.78 & 190.02 & 66.75 & 0.175 & 0.203 \\
8 & 19.25 & 7.73 & 2.41 & 15.75 & 41.85 & 7.28 & 193.75 & 58.29 & 0.184 & 0.224 \\
9 & 19.24 & 6.38 & 2.74 & 16.4 & 51.34 & 7.67 & 201.83 & 67.62 & 0.184 & 0.259 \\
10 & 19.18 & 8.96 & 2.48 & 16.46 & 46.43 & 7.87 & 190.92 & 67 & 0.181 & 0.236 \\
11 & 18.99 & 7.87 & 2.3 & 16.62 & 46.67 & 7.81 & 194.08 & 66 & 0.177 & 0.207 \\
12 & 19.17 & 7.41 & 2.17 & 17.12 & 41.76 & 7.42 & 182.75 & 65.17 & 0.168 & 0.215 \\
13 & 19.22 & 9.07 & 2.22 & 15.97 & 42.75 & 7.85 & 201.42 & 65.29 & 0.176 & 0.211 \\
mean & 18.99 & 8.58 & 2.3 & 16.35 & $43.82 a$ & 7.66 & 195.99 & 65.95 & 0.215 & 0.236 \\
\hline
\end{tabular}

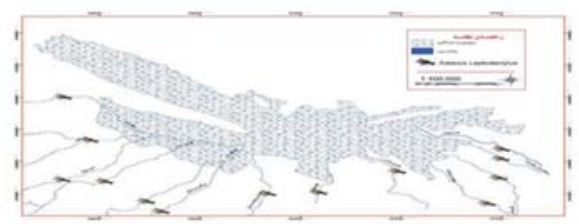

Figure 4 - Maps locke where species have average conditions for gromth.

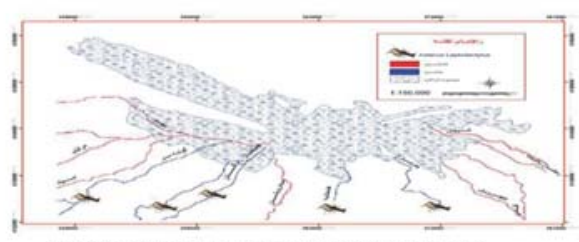

Figure 5-Map of where to locate are never out of the lower and upper limits

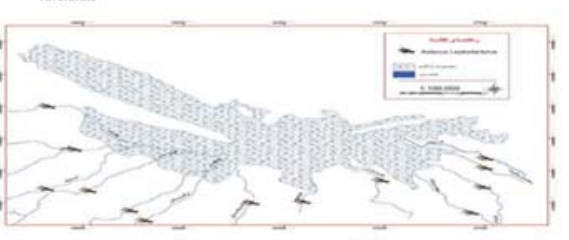

Figure 6. Map of scope for growth in 1370 


\section{Results}

The result of present research and the result of wetland potential trend investigation was shown during the past decade. The results indicated that the mean temperature between 18/39 to 19/25 C and average minimum and maximum of dissolved Oxygen is variable respectively, in 1 to 13 stations and 69 and 6/23ppm are the amount proportionate to optimum need. Such concluding was seen in for research and the others in 2000( Decker H, Foll R.,2000). Also, the amount of Calcium need for growth is the most important elements in 13 stations ranged between 58/29 to 67/39 was variable that these values are in the desirable levels and it doesn't seem that Calcium is being as a limiting factor for Caryfish growth in Anzali wetland .Cary fish has optimum physiological capacity for inhabiting pH 5 and these values are proportionate to obtained values from related 28 stations average from 7 to $187 \ldots \ldots \ldots . .$. researches and the others shown that it has many applications in crayfish breeding. The result show that the ........ of crayfish in Anzali wetland have been changed tremendously and this is worriable. It seems that the other effective factors on spices decreasing such as ecological significant changes Caspian Sea water instability, variable atmospheric fallings, entrance of Azola, diseases and hunter have been observed objectively in recent years.

\section{Discussion}

The analysis of water parameters from 13 stations in eastern, centeral est and west parts leading to Anzali wetland was done for economically importance of Astacus Leptodactylus ,decreasing change trends was investigated 86 statistics and the past decade census was analyzed to determine decreasing reasons. Totally information about this species, especialys after 1369 (Karimpour, M., Hosseinpour, N., Haghighi, D., 1988) and present research in 1368. It is difficult to determine effective factors in decreasing in this wetland. Of course, increasingly population so increasing pollutant charge from around city into this unique wetland also is one of the factor to significant ecologically changes in this place.600 thousand hector of rice paddies, agricultural orchard in north of Iran are the most reasons of consumption of pesticide and herbicide in this areas that 230 hector is located in Gillan. This amount is indicator for water resources pollution through agricultural sewages in this province then Anzali wetland. Some biologic and unbiologic factor could be effective on affluent pattern in Caryfish including: Temperature, water quality,pollutions, habitat structure, physical disturbance, competition and predation (Nystrom P., 2002). Nonbiological factors such as Crayfish temoreature,pH , dissolved oxygen, nutrient, water quality and habitat composition are involved and biological factors can include individual and social factors related to nutrition (food and predation) and parameters such as density, behavior, age and pubertal status( Reynolds J.D., 2002). While above factors can change in growth status, increasing in skin size and molting affluent (Jussila J, Evans L.1996) Crustaceans growth only was done in above certain temperature and with increasing temperature to related desirable amount, growth also increased. Temperature has effective on molting period. In temperature below desired amounts, Caryfish decrease the amount of feeding and drastic changes in Temperature or high amount can be lead to molting effect and increasing mortality after molting( Decker H, Foll R.,2000).Calcium is the most important element for the growth of crustaceans, The need for calcium is high after molting ,because, in this process, the high amount of cuticles shell calcium has been removed or reuptake by Asetatolyte. Cary fish has low calcium in water with low hardness relation to the same species in water with high hardness (Wheatky M.G Ayers J., 1999). Factors influencing the decline crayfish reserves in Anzali wetland including increasing in in pollution diseases possibly recent droughts, entrance of Anzali, shrimp macrobrachyim leaving the perch fry and hunter also increased reducing the average depth and sedimentation and salt water retention pond or shelf water salinity especially during the past during the past two years also can named. In present, the only way to improve crayfish population in this wetland is reconstruction reserves and introduction cary fish from itself (wetland) and in lacking of appropriate reserves, from the other pool like Aras dam lake into the wetland.

\section{Refrences}

Scholtz G., Richter S., 1995., phylogenic systematic of the Reptantian Decapoda (crustacean , Mala costraca). Zoological journal of the Linnaean society, P.289-328.

Harhoglu M.,2003., The present situation of fresh water cray fish , Astacus leptodactilus in Turkey . Faculty of Aquaculture, Firat university , 23119 , Elazig, P.181-187.

Koksal G.1988.,, Astacus leptodactylus in Europe . in : Fresh water cray fish : Biology , Management and Exploitation, P.365-400.

WWA(water work Association),. 2005., Standard Method for water and waste water Analysis, P. 125

Karimpour, M., Hosseinpour, N., Haghighi, D., 1988., Pilot evaluation of Astacus leptodactylus resources in Anzali wetland, FAO project, Iranian fisheries organization, P. 28-40. 
Nystrom P., 2002., Ecology In : Biology of fresh water cary fish, Holdich, P. 192-235.

Reynolds J.D., 2002., Growth and reproduction in: Holdich, D.M. Biology of fresh water cray fish, p .152-184.

Jussila J, Evans L., on the factors affecting marron, cherax tenuimanus, growth in tensive culture fresh water cray fish ; $1996 ; p .400$ 428.

Decker H , Foll R.,2000., Temperature adaptation in flounces the aggregation state of hemocyanin from Astacus leptodactylus . comparative Biochemistry and physiology, p. 147-154.

Wheatky M.G Ayers J., 1999., Scaling of calcium inorganic contents and organic contents to body mass during the modeling cycle of the fresh water cray fish procambrus clarkia (Givard); journal of crustacean Biology, p .409. 